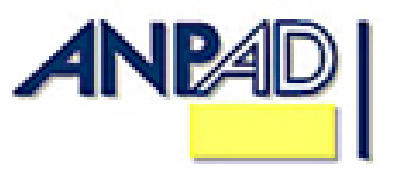

\author{
Disponível em \\ http://www.anpad.org.br/rac \\ RAC, Rio de Janeiro, v. 18, n. 5, art. 1, \\ pp. 551-576, Set./Out. 2014 \\ http://dx.doi.org/10.1590/1982-7849rac20141043 \\ $(\mathrm{cc})$ EY-NG
}

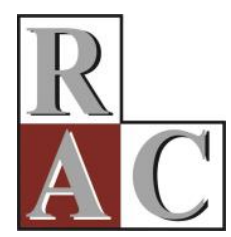

\title{
Redes, Inovação e Desempenho Exportador: Uma Abordagem Institucional
}

\author{
Exporter Networks, Innovation, and Performance: An Institutional Approach
}

Ilisangela Mais

E-mail: ilimais@gmail.com

Universidade Regional de Blumenau - FURB Rua Antônio da Veiga, 140, 89010-971, Blumenau, SC, Brasil.

Luciano Castro de Carvalho

E-mail: luccar@gmail.com

Universidade Regional de Blumenau - FURB

Rua Antônio da Veiga, 140, 89010-971, Blumenau, SC, Brasil.

Mohamed Amal

E-mail: mohamedamal.amal@gmail.com

Universidade Regional de Blumenau - FURB

Rua Antônio da Veiga, 140, 89010-971, Blumenau, SC, Brasil.

Artigo recebido em 15.08.2012. Última versão recebida em 19.04.2014. Aprovado em 31.05.2014. 


\title{
Resumo
}

Diversos estudos prévios buscaram analisar os fatores determinantes do desempenho exportador. Parte significativa desses estudos tem se dedicado à avaliação do papel dos recursos das empresas, gerenciais, organizacionais, assim como do tamanho e experiência da empresa. Outros procuraram medir o efeito da inovação sobre o desempenho exportador. Contudo há poucos estudos que tratam do efeito do quadro institucional sobre o desempenho exportador. O presente estudo tem como objetivo avaliar os determinantes institucionais do desempenho exportador de empresas, com isso, procurando preencher uma lacuna na literatura de negócios internacionais ao analisar os modos pelos quais o quadro institucional do país de origem afeta o desempenho exportador de empresas. Embora diversos estudos tenham investigado o efeito das instituições do país de origem sobre internacionalização e desempenho exportador, ainda são poucos aqueles que avaliaram os modos e mecanismos pelos quais tais instituições agem e configuram o desempenho exportador de empresas. A contribuição do presente estudo é, a partir de modelagem de equações estruturais, mostrar que o quadro institucional não tem efeito direto sobre o desempenho exportador, mas age de maneira indireta, por meio de mecanismos específicos de transmissão. Tal abordagem aponta para redes de relacionamento e inovação como dois mecanismos que desempenham funções específicas para configurar os efeitos das instituições. Conquanto os resultados empíricos não tenham apontado significância da dimensão inovação, as redes mostram-se como mecanismo específico para transmitir os efeitos do quadro institucional sobre o desempenho exportador.

Palavras-chave: desempenho exportador; inovação; instituições; redes.

\begin{abstract}
Several studies have attempted to analyze the determinants of export performance. Most of them have been dedicated to assessing the role of corporate, managerial, and organizational resources, as well as company size and experience. Others sought to measure the effect of innovation on export performance. However, there are few studies that address the effect institutional framework has on export performance. The present study aims to evaluate the institutional determinants of companies' export performance, seeking to fill a gap in the international business literature by examining the ways in which the institutional framework of the country of origin affects companies' export performance. Although several studies have investigated the effect country of origin institutions have on internationalization and export performance, there are few studies that have evaluated the modes and mechanisms by which such institutions act and shape companies' export performance. This study's contribution is using structural equation modeling to show that institutional framework has no direct effect on export performance, but acts indirectly through specific transmission mechanisms. This approach points to social networks and innovation as two mechanisms that perform specific functions to configure institutional effects. Although the empirical results did not show statistical significance for the innovation dimension, the network mechanism has been shown as a specific and efficient mechanism for transmitting institutional framework effects on export performance.
\end{abstract}

Key words: export performance; innovation; institutions; network. 


\section{Introdução}

A globalização das economias tem contribuído significativamente para a expansão internacional das empresas, não apenas de origem de países desenvolvidos, mas, também, daqueles em desenvolvimento. Este fenômeno abrange, além das empresas multinacionais, pequenas e médias empresas, tornando as estratégias de internacionalização, nesta era de interdependência dos mercados, um objetivo importante para sustentar as estratégias de crescimento das empresas. Embora os fluxos de investimento estrangeiro direto venham crescendo significativamente ao longo dos anos de 1990 e 2000 (com curtos períodos de recuo na crise de 2008), as exportações continuam representando a maior parte das transações internacionais de empresas de países em desenvolvimento e sustentam, em larga escala, os seus modos de entrada em mercados externos, bem como seu desempenho internacional. Neste sentido, o estudo dos fatores determinantes do desempenho exportador representa um passo importante para o entendimento dos padrões e estratégias de internacionalização de empresas, além de poder contribuir com as preocupações gerenciais das empresas de buscar um melhor posicionamento no mercado internacional.

No estudo do processo de ingresso das empresas no mercado internacional, a abordagem de Uppsala (Johanson \& Vahlne, 1977) tem sido uma das principais referências teóricas. Porém, atualmente, há novos fatores sendo considerados na proposição de teorias, que passaram a contemplar, por exemplo, as redes de relacionamento, a inovação e as características empreendedoras (Mathews \& Zander, 2007; Moen, Gavlen, \& Endresen, 2004; Weerawardena, Mort, Liesch, \& Knight, 2007). Tais abordagens contribuíram significativamente para fornecer novas perspectivas de avaliação dos fatores determinantes da internacionalização de empresas de modo geral e, mais especificamente, do desempenho exportador de empresas.

Diversos estudos empíricos e teóricos buscaram analisar os fatores determinantes do desempenho exportador. Uma parte significativa dos estudos sobre os determinantes do desempenho exportador tem se dedicado à avaliação do papel dos recursos das empresas, gerenciais, organizacionais, tamanho, experiência com os mercados externos (Carneiro, Rocha, \& Silva, 2009, 2011; Klotzle \& Tomé, 2006; Majocchi, Bacchiocchie, \& Mayrhofer, 2005; Sousa \& Bradley, 2008), e outros estudos procuraram medir o efeito da inovação sobre o desempenho exportador, tais como Filipescu, Rialp e Rialp (2009), Lee e Habte-Giorgin (2004), Pla-Barber e Alegre (2007), Rodriguez e Rodriguez (2005), Roper e Love (2002) e Singh (2009), entre outros.

Paralelamente ao desenvolvimento das perspectivas de recursos, a literatura de negócios internacionais tem se dedicado a incorporar as contribuições da teoria institucional (North, 1990) a fim de entender às restrições e aos limites do processo e desempenho internacional de empresas. Diversos estudos (Kostova, 1997; Kostova \& Zaheer, 1999; Scott, 1995; Xu \& Shenkar, 2002) procuraram introduzir o conceito de distância institucional (distância regulatória, normativa e cognitivo-cultural) para o entendimento das estratégias de internacionalização e os modos pelos quais empresas multinacionais gerenciam os custos decorrentes dos passivos de internacionalização (liability of foreignness). Contudo uma revisão da literatura, nos principais periódicos nacionais e internacionais, relata que há poucos estudos que tratam do efeito do quadro institucional sobre o desempenho exportador (Buckley \& Gauri, 2004; Kshetri, 2007; Loane \& Bell, 2006; Zhou, Wu, \& Luo, 2007).

Diante do exposto, o presente estudo tem como objetivo avaliar os determinantes do desempenho exportador de empresas através de uma perspectiva institucional. Mais especificamente, visa verificar de que modo se dá o efeito do quadro institucional do país de origem sobre o desempenho exportador. Neste trabalho, buscou-se mostrar que o quadro institucional age sobre o desempenho exportador através de dois mecanismos de transmissão: redes de relacionamento e inovação. Hollingsworth (2000), numa análise da perspectiva institucional, detectou que os mecanismos pelos quais o quadro institucional afeta o desempenho de empresas são diversos. Neste trabalho, procurou-se focalizar dois mecanismos principais: redes de relacionamento e inovação, que representam dimensões relevantes tanto do ponto de vista das teorias clássicas de negócios 
internacionais (Modelo de Uppsala, Johanson, \& Vahlne, 1977) quanto das novas contribuições do modelo com a introdução do papel das redes e da inovação na dinâmica e velocidade do processo de internacionalização (Johanson \& Vahlne, 2009). As redes são caracterizadas na dimensão de arranjos institucionais, na qual são expressas as relações hierárquicas e de cooperação entre empresas e das empresas com o Estado. A inovação é expressa pela dimensão Resultados e Desempenho, na qual são manifestadas as decisões administrativas e estratégicas.

O presente trabalho procura preencher, portanto, uma lacuna na literatura de negócios internacionais, respondendo a duas perguntas principais: (a) Quais são os efeitos do quadro institucional sobre o desempenho exportador?; (b) Considerando que o efeito do quadro institucional nem sempre é direto, através de quais mecanismos o quadro institucional exerce tais efeitos sobre o desempenho exportador?

Para tanto, o artigo está organizado da seguinte maneira: primeiro, discutem-se os fundamentos teóricos do estudo e apresentam-se as hipóteses. Em seguida, definem-se os procedimentos metodológicos, apresentação e discussão dos resultados. Finalmente, são apresentadas as principais conclusões do estudo.

\section{Revisão de Literatura}

A revisão de literatura contempla diferentes áreas do conhecimento com o intuito de ajudar a desenvolver o quadro teórico que dá suporte às proposições do estudo, sobressaindo os estudos prévios sobre desempenho exportador, instituições, inovação e redes.

\section{Desempenho exportador}

Conhecer os determinantes do desempenho exportador das empresas é um objetivo constante entre os pesquisadores de negócios internacionais (Carneiro et al., 2011; Klotzle \& Thomé, 2006; Mais \& Amal, 2011; Majocchi et al., 2005; Pla-Barber \& Alegre, 2007; Singh, 2009, Stoian, Rialp, \& Rialp, 2011). Existe, no entanto, uma falta de consenso atinente à definição de medidas adequadas para avaliação do desempenho exportador, o que compromete a comparação de diferentes estudos e prejudica a evolução das teorias de negócios internacionais.

Embora haja um estoque significativo de estudos relativos ao desempenho exportador, ainda são muito escassas as investigações sobre o papel das instituições do país de origem quanto ao desempenho exportador e, especialmente, a respeito dos modos como tais instituições agem e configuram o desempenho internacional de empresas. Os estudos existentes no Brasil têm focalizado particularmente o papel dos recursos e da distância psíquica entre país de origem e de destino (Carneiro et al., 2009), ou de estudos, com uma perspectiva de abordagem qualitativa, dos efeitos das instituições sobre os diferentes modos de entrada e de desempenho exportador (Mais \& Amal, 2011). Outros estudos procuraram avaliar o efeito de variáveis macroeconômicas, como a taxa de câmbio como determinante do desempenho exportador (Puga, 2006). Entretanto tais estudos utilizaram variáveis agregadas, o que não permite verificar os efeitos sobre empresas.

Para utilizar, neste estudo, um indicador já empregado e aceito nas pesquisas de negócios internacionais, foram revisados 30 estudos prévios que analisaram o desempenho exportador. E, assim, optou-se por focalizar os estudos sobre as empresas, descartando aqueles que se centraram no desempenho das nações por se tratar do uso de fatores macroeconômicos para o entendimento do desempeno da variável agregada de exportação.

Como resultado da revisão, utilizou-se como indicador a intensidade exportadora (total de exportações dividido pelo faturamento global da empresa) e a diversificação das exportações medida pelo número de mercados atendidos pela exportação. Tal escolha se baseia no fato de se tratar do 
indicador predominante entre os trabalhos revisados, apresentados na Tabela 1. Entende-se, ainda, que o indicador é adequado para avaliar empresas de diferentes portes e estágios de desenvolvimento, pois demonstra a importância relativa da atividade para a empresa. Adicionalmente, utilizou-se como indicador de desempenho exportador o número de países atendidos pelas empresas pesquisadas, para dar mais consistência aos dados obtidos.

Tabela 1

Estudos Prévios de Desempenho Exportador

\begin{tabular}{|c|c|c|c|}
\hline Autores & Medida de desempenho & $\begin{array}{l}\text { Determinantes do desempenho - } \\
\text { Efeito positivo (+) ou negativo (-) }\end{array}$ & $\begin{array}{l}\text { Abordagens } \\
\text { teóricas }\end{array}$ \\
\hline $\begin{array}{l}\text { Alvarez (2004 como } \\
\text { citado em Singh, 2009) }\end{array}$ & $\begin{array}{l}\text { Intensidade } \\
\text { exportadora. }\end{array}$ & $\begin{array}{l}\text { Esforços para os negócios } \\
\text { internacionais, inovações de } \\
\text { processo e programas de promoção à } \\
\text { exportação }(+) \text {. }\end{array}$ & $\begin{array}{l}\text { Inovação + } \\
\text { promoção }\end{array}$ \\
\hline $\begin{array}{l}\text { Aulakh, Kotabe e } \\
\text { Teegen (2000 como } \\
\text { citado em Klotzle \& } \\
\text { Thomé, 2006) }\end{array}$ & $\begin{array}{l}\text { Crescimento e } \\
\text { lucratividade das } \\
\text { exportações e market- } \\
\text { share. }\end{array}$ & $\begin{array}{l}\text { Estratégia de custos baixos (+); } \\
\text { diversificação de mercados/países (+). }\end{array}$ & Estratégias \\
\hline $\begin{array}{l}\text { Baldauf, Cravens e } \\
\text { Wagner ( } 2000 \text { como } \\
\text { citado em Singh, 2009) }\end{array}$ & $\begin{array}{l}\text { Intensidade } \\
\text { exportadora, volume de } \\
\text { vendas externas e } \\
\text { efetividade exportações. }\end{array}$ & $\begin{array}{l}\text { Tamanho da empresa, motivos dos } \\
\text { gestores para internacionalização e } \\
\text { uso de estratégia de diferenciação } \\
(+) \text {. }\end{array}$ & $\begin{array}{l}\text { Tamanho + } \\
\text { inovação }\end{array}$ \\
\hline $\begin{array}{l}\text { Bijmolt e Zwart (1994 } \\
\text { como citado em Klotzle } \\
\text { \& Thomé, 2006) }\end{array}$ & $\begin{array}{l}\text { Intensidade } \\
\text { exportadora, satisfação } \\
\text { com a atividade e } \\
\text { rentabilidade e } \\
\text { crescimento das } \\
\text { exportações. }\end{array}$ & $\begin{array}{l}\text { Estrutura interna voltada para as } \\
\text { exportações }(+) \text {; gestores proativos } \\
(+) \text {. }\end{array}$ & Recursos \\
\hline $\begin{array}{l}\text { Cadogan, } \\
\text { Diamantopoulos e } \\
\text { Siguaw (2002 como } \\
\text { citado em Singh, 2009) }\end{array}$ & $\begin{array}{l}\text { Crescimento das vendas } \\
\text { externas. }\end{array}$ & $\begin{array}{l}\text { Atividades orientadas para o mercado } \\
\text { externo - grau da orientação de } \\
\text { mercado aos mercados externos }(+) \text {. }\end{array}$ & Recursos \\
\hline Carneiro et al. (2009) & $\begin{array}{l}\text { Receitas e lucratividade } \\
\text { passadas da exportação. }\end{array}$ & $\begin{array}{l}\text { Status da atividade de exportação (+); } \\
\text { barreiras no país de destino }(-) \text {. }\end{array}$ & Institucionais \\
\hline Carneiro et al. (2011) & $\begin{array}{l}\text { Receitas, crescimento das } \\
\text { receitas e lucratividade da } \\
\text { exportação. }\end{array}$ & $\begin{array}{l}\text { Distância psíquica (sem efeito), } \\
\text { distância de negócios (sem efeito), } \\
\text { barreiras no país de destino (-), status } \\
\text { da atividade de exportação (+), } \\
\text { planejamento sistemático das } \\
\text { exportações (+). }\end{array}$ & $\begin{array}{l}\text { Institucionais + } \\
\text { recursos }\end{array}$ \\
\hline $\begin{array}{l}\text { Dean, Mengüç e Myers } \\
\text { (2000 como citado em } \\
\text { Klotzle \& Thomé, } \\
\text { 2006) }\end{array}$ & $\begin{array}{l}\text { Volume de vendas } \\
\text { externas, intensidade } \\
\text { exportadora e } \\
\text { crescimento exportações. }\end{array}$ & $\begin{array}{l}\text { Tamanho da empresa }(+), \text { tempo de } \\
\text { atuação no mercado internacional }(+), \\
\text { diversificação de mercados/países } \\
(+) \text {; gestores proativos }(+) .\end{array}$ & Recursos \\
\hline $\begin{array}{l}\text { Estrin et al. (2008 como } \\
\text { citado em Singh, 2009) }\end{array}$ & $\begin{array}{l}\text { Intensidade } \\
\text { exportadora. }\end{array}$ & $\begin{array}{l}\text { Liberdade no ambiente econômico } \\
\text { institucional do país de destino (-); } \\
\text { tamanho da empresa matriz (sem } \\
\text { efeito). }\end{array}$ & $\begin{array}{l}\text { Institucionais + } \\
\text { recursos }\end{array}$ \\
\hline
\end{tabular}


Tabela 1 (continuação)

\begin{tabular}{ll}
\hline Autores & Medida de desempenho \\
\hline $\begin{array}{l}\text { Filatotchev } \text { et al. (2008 } \\
\text { como citado em Singh, }\end{array}$ & $\begin{array}{l}\text { Intensidade } \\
\text { exportadora. }\end{array}$ \\
Filatotchev, Dyomina, & Intensidade \\
Wright e Buck (2001 & exportadora \\
como citado em Singh, & \\
2009) & \\
Gomel (2005) & $\begin{array}{l}\text { Total de exportação; } \\
\text { Intensidade } \\
\text { exportadora; total de } \\
\text { lucro e intensidade de } \\
\text { lucratividade com } \\
\text { exportações. }\end{array}$ \\
& $\begin{array}{l}\text { Intensidade } \\
\text { exportadora e percepção } \\
\text { sobre crescimento de } \\
\text { vendas externas. }\end{array}$ \\
$\begin{array}{ll}\text { Haahti, Madupu, Yavas } \\
\text { e Babakus (2005 como } \\
\text { citado em Singh, 2009) }\end{array}$ & $\begin{array}{l}\text { Intensidade } \\
\text { exportadora; frequência } \\
\text { exportadora; } \\
\text { diversificação das } \\
\text { exportações. }\end{array}$ \\
Klotzle e Thomé (2006 & \\
&
\end{tabular}

Kuivalainen, Sundqvist Volume, desempenho de e Servais (2007) lucro e efetividade das vendas externas.
Lages, Jap e Griffith (2008 como citado em Singh, 2009)

\section{Lee e Habte-Giorgis (2004)}

Leonidou, Katsikeas e Samiee (2002)

\section{Intensidade exportadora. \\ Intensidade exportadora.}

Volume de vendas externas, intensidade exportadora, lucratividade $\mathrm{e}$ crescimento das exportações.

Ling-yee e Ogunmokun (2001 como citado em Klotzle \& Thomé, 2006)
Crescimento das exportações, aumento de venda e alcance dos objetivos e metas das firmas.
Intensidade de conhecimento (+); regula a relação entre estratégias de cooperação e desempenho exportador.

Experiência no mercado internacional (+); departamento específico para a atividade exportadora (+); utilização de linhas específicas de financiamento (ACC) (+); qualidade do produto $(+)$.

Ser uma verdadeira empresa born global (+).

Comprometimento com a exportação (+).

Diversificação de produto (+); intensidade de $\mathbf{P} \& \mathbf{D}$ e tamanho da empresa (+).

Estratégias de marketing.

Inovação + marketing

Recursos + redes

Inovação

Abordagens teóricas

Recursos

$(+)$; controle sobre as decisões

Desenvolvimento de produtos (+); aquisição internacional (sem efeito); presença de

Capacitação tecnológica (+) (ações de incentivo e contribuição de novos produtos ao faturamento).

Experiência + recursos + institucional

Empreendedorismo internacional

Recursos

Inovação

Marketing

Vantagens de exportação percebidas pelos gestores $(+)$; canal de

Mercado + distribuição e financiamentos à institucional exportação $(+)$. 
Tabela 1 (continuação)

\begin{tabular}{|c|c|c|c|}
\hline Autores & Medida de desempenho & $\begin{array}{l}\text { Determinantes do desempenho - } \\
\text { Efeito positivo (+) ou negativo (-) }\end{array}$ & $\begin{array}{l}\text { Abordagens } \\
\text { teóricas }\end{array}$ \\
\hline Mais e Amal (2011) & $\begin{array}{l}\text { Intensidade } \\
\text { exportadora. }\end{array}$ & $\begin{array}{l}\text { Quadro institucional - especialmente } \\
\text { benefícios tributários e financeiros } \\
(+) \text {, inovação }(+) \text { e redes }(+) .\end{array}$ & $\begin{array}{l}\text { Instituições + } \\
\text { inovação }\end{array}$ \\
\hline Majocchi et al. (2005) & $\begin{array}{l}\text { Intensidade } \\
\text { exportadora. }\end{array}$ & $\begin{array}{l}\text { Tamanho da empresa (+); idade da } \\
\text { empresa ou experiência de mercado } \\
(+) .\end{array}$ & $\begin{array}{l}\text { Recursos + } \\
\text { experiência }\end{array}$ \\
\hline $\begin{array}{l}\text { Papadopoulos e Martín } \\
\text { Martín (2010) }\end{array}$ & $\begin{array}{l}\text { Rentabilidade percebida, } \\
\text { volume de exportações, } \\
\text { desempenho estratégico. }\end{array}$ & $\begin{array}{l}\text { Internacionalização (+), experiência } \\
\text { internacional }(+) \text {, comprometimento } \\
\text { internacional }(+) \text {. }\end{array}$ & $\begin{array}{l}\text { Experiência + } \\
\text { recursos }\end{array}$ \\
\hline $\begin{array}{l}\text { Peng e York ( } 2001 \\
\text { como citado em Singh, } \\
2009)\end{array}$ & $\begin{array}{l}\text { Margem líquida de } \\
\text { vendas externas, vendas } \\
\text { externas por funcionário. }\end{array}$ & $\begin{array}{l}\text { Conhecimento do intermediário }(+) \text {; } \\
\text { envolvimento do intermediário com o } \\
\text { produto }(+) \text {. }\end{array}$ & Recursos \\
\hline $\begin{array}{l}\text { Pla-Barber e Alegre } \\
(2007)\end{array}$ & $\begin{array}{l}\text { Intensidade } \\
\text { exportadora. }\end{array}$ & $\begin{array}{l}\text { Inovação (+); tamanho da empresa } \\
\text { (sem efeito). }\end{array}$ & Inovação \\
\hline $\begin{array}{l}\text { Rodriguez e Rodriguez } \\
\text { (2005) }\end{array}$ & $\begin{array}{l}\text { Intensidade } \\
\text { exportadora. }\end{array}$ & $\begin{array}{l}\text { Inovação no produto }(+) \text {; patentes e } \\
\text { inovações de processo }(+) \text {; gastos } \\
\text { com P\&D em relação ao } \\
\text { faturamento }(+) \text {. }\end{array}$ & Inovação \\
\hline Roper e Love (2002) & $\begin{array}{l}\text { Intensidade } \\
\text { exportadora, } \\
\text { probabilidade de } \\
\text { exportação. }\end{array}$ & Inovação no produto $(+)$. & Inovação \\
\hline Singh (2009) & $\begin{array}{l}\text { Vendas externas totais e } \\
\text { vendas internas totais. }\end{array}$ & $\begin{array}{l}\text { Gastos com P\&D (+) Gastos com } \\
\text { propaganda (-) Afiliação a um grupo } \\
(+) \text {. Vendas domésticas (+) } \\
\text { (interdependência entre vendas } \\
\text { externas e internas). }\end{array}$ & Inovação \\
\hline $\begin{array}{l}\text { Sousa e Bradley ( } 2008 \\
\text { como citado em Singh, } \\
\text { 2009) }\end{array}$ & Múltiplos indicadores. & $\begin{array}{l}\text { Experiência internacional do gestor } \\
(+) \text {; características do mercado } \\
\text { externo (estratégias de preços) }(+) \text {. }\end{array}$ & $\begin{array}{l}\text { Experiência e } \\
\text { mercados }\end{array}$ \\
\hline $\begin{array}{l}\text { Stoian, Rialp e Rialp } \\
\text { (2011) }\end{array}$ & $\begin{array}{l}\text { Intensidade } \\
\text { exportadora, número de } \\
\text { países atendidos, zonas } \\
\text { de mercado atendidas, } \\
\text { indicadores subjetivos. }\end{array}$ & $\begin{array}{l}\text { Habilidades em idiomas e } \\
\text { conhecimento de negócios } \\
\text { internacionais dos gestores }(+), \\
\text { experiência e comprometimento da } \\
\text { empresa com exportações }(+), \\
\text { intensidade tecnológica }(+) \text {. }\end{array}$ & $\begin{array}{l}\text { Experiência + } \\
\text { institucional }+ \\
\text { organizacional }\end{array}$ \\
\hline $\begin{array}{l}\text { Verwaal e Donkers } \\
\text { (2002) }\end{array}$ & $\begin{array}{l}\text { Intensidade } \\
\text { exportadora. }\end{array}$ & Tamanho das redes internacionais $(+)$. & Redes \\
\hline
\end{tabular}

Nota. Fonte: dados da pesquisa.

\section{Determinantes do desempenho exportador das empresas}

$\mathrm{O}$ estudo dos fatores determinantes do desempenho exportador tem sido tema recorrente nas publicações nacionais e internacionais nos últimos anos. Pela Tabela 1, denota-se que, dos 30 artigos revisados, 16 buscaram discutir o papel dos recursos da empresa na determinação de seu desempenho exportador. Como recursos, entende-se os recursos próprios da empresa (tecnológicos, financeiros, produtivos, humanos) ou os recursos da rede na qual a empresa está inserida. Em segundo lugar, 10 artigos procuraram medir o efeito da inovação no desempenho exportador das empresas, e, finalmente, 
apenas sete dos artigos revisados efetivamente procuraram avaliar os efeitos do ambiente institucional sobre o desempenho exportador de empresas. Neste artigo, procura-se identificar as relações entre instituições, inovação, redes e desempenho exportador. Mais especificamente, como interagem os fatores e através de quais mecanismos o quadro institucional age sobre o desempenho exportador de empresas.

\section{Efeitos do quadro institucional sobre a inovação e o desempenho exportador}

North (1990) afirma que as instituições podem ser interpretadas como as regras do jogo que orientam uma sociedade, incluindo aspectos formais e informais que definem comportamentos, relações, padrões de desempenho e de atuação aceitos e valorizados naquele ambiente.

Para North (1990), as instituições possuem três dimensões: regras formais, restrições informais e os mecanismos de aplicação. As regras formais incluem regras políticas, econômicas e contratos. Enquanto as regras políticas definem uma estrutura hierárquica, a econômica define os diretos de propriedade e da capacidade de alienar ativos ou recursos, já os contratos contêm provisões específicas para acordos em particular.

De acordo com North (1990) e Scott (1995), as restrições informais são regras impostas pelos humanos sobre eles mesmos, no entanto não são regras percebidas com facilidade, mas têm uma enorme capacidade de estruturar as relações humanas. Entre os tipos de restrições informais, há os códigos de conduta, as normas de comportamento e convenções. Quanto aos mecanismos de aplicação, estes estão diretamente relacionados aos custos de transações e são empreendidos por agentes que assumem uma função que influencia diretamente nos resultados (North, 1990). Tal abordagem significa que não há uma única dimensão que determine as relações entre os agentes e menos ainda uma dimensão que possa se sobrepor unilateralmente às demais dimensões do quadro institucional (Wood \& Demirbag, 2012).

Nesta perspectiva de configuração do ambiente institucional, as instituições tendem a interagir com as organizações, o que resulta num quadro institucional de restrições e oportunidades (North, 1990). A partir de tal configuração do ambiente institucional, as estratégias e desempenho das organizações são afetados e reorientados de modo a gerenciarem os custos de transação e riscos decorrentes de tais mudanças. Para Scott (1995), tal ambiente, por incluir diversos níveis: regulatório, normativo e cognitivo-cultural, apresenta graus de complexidade elevados, impondo desafios e constituindo-se num fator determinante do desempenho das organizações.

Hollingsworth (2000) propôs que, na medida em que as instituições restringem a ação dos membros de uma nação, exercem efeito direto sobre diversos indicadores relacionados à competitividade empresarial, dedicando especial atenção ao grau de inovação observado naquela nação. Para subsidiar seus estudos, propôs cinco níveis de análise do quadro institucional, cuja organização baseou-se nas características de permanência e estabilidade dos itens identificados, com base em autores de várias áreas do conhecimento, conforme a Tabela 2, a seguir:

Tabela 2

Componentes da Análise Institucional

1 Instituições =

2 Arranjos institucionais $=$

3 Setores institucionais $=$ normas, regras, convenções, hábitos e valores (Burns \& Flam, 1987; North, 1990).

mercados, estados, hierarquias corporativas, redes, associações, comunidades (Campbell, Hollingsworth, \& Lindberg, 1991; Hollingsworth \& Lindberg, 1985; Hollingsworth, Schmitter, \& Streeck, 1994).

sistema financeiro, de educação, de negócios, de pesquisa (Hollingsworth, 1997). 


\section{Tabela 2 (continuação)}

\begin{tabular}{ll}
\hline Organizações = & (Powell \& DiMaggio, 1991). \\
5 Resultados e desempenho $=$ & estatutos; decisões administrativas, natureza, quantidade e qualidade dos \\
& produtos industriais (Hollingsworth, 1991, 1997); desempenho setorial e da \\
& sociedade (Hollingsworth \& Streeck, 1994; Hollingsworth, Hage, \& \\
& Hanneman, 1990; Hollingsworth \& Hanneman, 1982). \\
\hline
\end{tabular}

Nota. Fonte: adaptada de Hollingsworth, J. R. (2000). Doing institutional analysis: implications for the study of innovations. Review of International Political Economy, 7(4), 595-644. doi: 10.1080/096922900750034563

Utilizando como referência os itens propostos por Hollingsworth (2000), pode-se estimar que o quadro institucional também exerça efeito sobre o desempenho exportador das empresas, por meio de mecanismos como: grau de sofisticação dos mercados, com efeito sobre os padrões de qualidade dos produtos (Porter, 1999; Roper \& Love, 2002), padrões culturais e de negociações (Kshetri, 2007), estabelecimento e finalidade das redes de cooperação (Zhou et al., 2007), existência de incentivos formais para internacionalização (Diegues \& Roselino, 2006), padrões de gestão do conhecimento e estratégias de inovação (Lu, Tsang, \& Peng, 2008), estratégias de internacionalização como resultado da pressão mimética (Cheng \& Yu, 2008), por exemplo. Adicionalmente, estudos anteriores relatam uma relação entre a importância das redes de relacionamento e a existência de instituições fortes em um país (Meyer, Estrin, Bhaumik, \& Peng, 2009; Zhou et al., 2007). Tais estudos demonstram que as redes de relacionamento amenizam a eventual falta de confiança institucional e podem determinar os padrões de entrada de investimentos estrangeiros.

Ao estudarem os efeitos das instituições sobre a internacionalização de empresas, Mais e Amal (2011) sugerem que o quadro institucional diretamente relacionado possa ser representado por: organismos de suporte a negócios internacionais, políticas governamentais locais, sistema de financiamento disponível, normas, regras, hábitos, costumes e valores observados na sociedade. Tais itens exerceriam efeito na definição das estratégias das empresas no processo de internacionalização, indiretamente, afetando seu desempenho exportador.

Para subsidiar as perguntas de pesquisa do presente estudo sobre os efeitos do quadro institucional e os modos e mecanismos por meio dos quais ele age no tocante ao desempenho exportador, procurou-se formular hipóteses específicas para cada uma das dimensões do modelo proposto.

Neste sentido, as redes passam a representar um quadro de relacionamento entre empresas que permite suprir as deficiências institucionais e representar as condições para as empresas construírem competências específicas para a sua inserção competitiva nos mercados externos (Awuah \& Amal, 2011; Peng, Sun, Pinkham, \& Cheng, 2009). A inserção em redes também pode compensar as restrições impostas pela distância institucional entre país de origem e de destino, mas, sobretudo, tende a constituir uma resposta estratégica para as restrições impostas pelo próprio ambiente institucional do país de origem.

A revisão dos estudos relatados subsidiou a formulação das hipóteses 1 e 2.

H1: O quadro institucional influencia positivamente na inserção das empresas em redes de cooperação.

H2: O quadro institucional influencia positivamente no desenvolvimento de inovações.

As hipóteses 1 e 2 buscam, particularmente, subsidiar a primeira pergunta do presente estudo referente ao papel das instituições e suas relações indiretas com o desempenho exportador de empresas, apontando que tal relação se dá através das dimensões de redes e desenvolvimento de inovações. Tais dimensões, como têm sido discutidas na literatura de Negócios Internacionais, constituem fatores críticos para o entendimento das estratégias e desempenho das empresas nos mercados externos. 


\section{Inserção em redes e desempenho exportador das empresas}

Avançando em relação ao modelo de envolvimento gradual das empresas nos mercados internacionais, Johanson e Mattson (1988) propuseram uma teoria segundo a qual as decisões das empresas, em termos de seleção de mercados e modo de entrada, seriam resultantes de sua posição nas redes de relacionamento, de acordo com sua posição na rede e o nível de internacionalização da própria rede. O nível de internacionalização de uma empresa seria, assim, reflexo não apenas dos recursos alocados no exterior, mas também do nível de internacionalização das redes em que está inserida (Amal \& Freitag, 2010).

Coviello e Munro (1995) argumentam que as relações existentes com os mercados são mais relevantes para o sucesso do que a escolha de mercados e suas características culturais, considerando que as relações existentes oferecem contatos e contribuem para o desenvolvimento de novos parceiros nos diferentes mercados. Tais redes contemplam as redes formais nas quais as empresas estão inseridas, mas também incluem a rede pessoal dos empreendedores (Harris \& Wheeler, 2005; Peng \& Heath, 1996) e facilitam o acesso à informação, recursos, mercados e tecnologias, assim, configurando um diferencial competitivo. De maneira complementar, o estudo do processo de internacionalização de pequenas e médias empresas taiwanesas, conduzido por Cheng e Yu (2008), resultou na identificação de que tais empresas, de forma individual, poderiam não perceber e aproveitar as oportunidades do mercado internacional, dessa maneira, ressaltando a importância e o papel das redes no início da internacionalização das empresas analisadas.

As redes também exercem efeito sobre outras atividades da empresa, com destaque para a geração de inovações. Tödtling e Kaufmann (2002) destacam, no processo de desenvolvimento de inovações, a relevância da integração entre a empresa e seu ambiente, incluindo a cooperação entre os setores da própria empresa e organismos externos, como clientes, fornecedores, instituições de pesquisa, provedores de recursos financeiros e governos. Tal abordagem da inovação, com uma perspectiva interativa, também está entre os fundamentos dos estudos sobre inovação de Schumpeter (1934) e Freeman (1995), por exemplo, que se contrapõem à visão de desenvolvimento das inovações como um processo linear e endógeno. Freeman (1995) argumenta que a inovação é resultado de um processo interativo e de permanente aprendizagem. Além de desenvolverem conhecimentos próprios a partir da sua experiência direta nas etapas de desenho, desenvolvimento, produção e comercialização, as empresas absorvem conhecimentos que derivam das suas relações com fontes externas, beneficiando-se da experiência desses parceiros.

Tendo em vista os resultados dos estudos citados, propôs-se as hipóteses 3 e 4 :

H3: A inserção em redes influencia positivamente no desenvolvimento de inovações.

H4: A inserção em redes influencia positivamente no desempenho exportador.

As hipóteses 3 e 4 buscam, particularmente, subsidiar a segunda pergunta do presente estudo, referente aos modos como o quadro institucional influencia o desempenho exportador de empresas. Tal perspectiva sugere que as redes, além de influenciarem na capacidade inovadora das empresas, agem diretamente sobre o seu desempenho exportador.

\section{O papel da inovação no desempenho exportador das empresas}

De acordo com Schumpeter (1934), a inovação é responsável pelo crescimento econômico das sociedades, com destaque para aquelas inovações que se caracterizam como produtos e serviços efetivamente novos, os quais criariam novos mercados e demandas. Com relação aos negócios internacionais, a relação entre inovação e o desempenho exportador tem sido apontada como uma possível explicação para o desempenho diferenciado das nações no comércio mundial (Filipescu, Rialp, \& Rialp, 2009; Roper \& Love, 2002). 
Kim e Mauborgne (2005), ao analisarem um período de 120 anos de 30 setores industriais norte-americanos, indicaram que o padrão mais persistente entre as empresas com alto crescimento estava relacionado a estratégias que resultaram na oferta de novos produtos e serviços, ocupando novos espaços no mercado, com efeitos relevantes sobre a demanda. No Brasil, Gomes e Kruglianskas (2009) identificaram os impactos mais relevantes da inovação entre 72 empresas reconhecidas como inovadoras: ampliação da gama de produtos ofertados, melhoria da qualidade dos produtos, aumento da capacidade de produção, entrada em novos mercados, ampliação da participação da empresa no mercado, melhoria em aspectos associados às regulamentações e normas do mercado interno e externo. O acesso a novos mercados é um dos efeitos frequentemente atribuídos às inovações (Filipescu et al., 2009; Knight \& Cavusgil, 2004; Roper \& Love, 2002), bem como a propensão das empresas a exportar (Nguyen, Quang Pham, Nguyen, \& Nguyen, 2008; Roper \& Love, 2002). De Negri e Freitas (2004), ao analisarem o caso do Brasil, reafirmam a relação entre a inovação e propensão à exportação, indicando que as empresas brasileiras que geram inovação tecnológica têm $16 \%$ mais chances de serem exportadoras do que aquelas que não desenvolvem inovações.

Os resultados apresentados levaram à formulação da hipótese 5:

H5: O desenvolvimento de inovações influencia positivamente no desempenho exportador.

A hipótese 5 busca, especificamente, subsidiar a segunda pergunta do presente estudo, referente ao papel da inovação como mecanismo pelo qual o quadro institucional age sobre o desempenho exportador das empresas. Tal dimensão, como tem sido discutida na literatura de Negócios Internacionais, representa um fator que contém o efeito não apenas de acelerar o desempenho exportador das empresas, mas, também, de diversificar a abrangência dos mercados externos onde atuam.

\section{Metodologia}

O presente estudo teve como objetivo avaliar os determinantes do desempenho exportador de empresas. Mais especificamente, visou verificar de que modo se dá o efeito do quadro institucional do país de origem sobre o desempenho exportador. Busca-se preencher uma lacuna na literatura de negócios internacionais, respondendo a duas perguntas principais: (a) Quais são os efeitos do quadro institucional sobre o desempenho exportador?; (b) Considerando que o efeito do quadro institucional nem sempre é direto, através de quais mecanismos o quadro institucional exerce tais efeitos sobre o desempenho exportador?

O presente estudo se caracterizou como uma pesquisa descritiva, com abordagem quantitativa. Foi conduzida na forma de levantamento, de corte transversal, e utilizou questionário eletrônico orientado para a descrição das características do objeto e o estabelecimento das relações entre as diferentes dimensões e variáveis. Segundo Yin (2005), o levantamento é uma estratégia de pesquisa adequada para obter respostas do tipo quem, o que, onde, quanto, quantos, sendo vantajosa para pesquisas que buscam "descrever a incidência ou a predominância de um fenômeno, quando ele for previsível sobre certos resultados” (p. 25).

\section{Amostra}

A população deste estudo foi composta pelas empresas estabelecidas no estado de Santa Catarina que realizaram exportações diretas no ano de 2008. Foram acessadas todas as empresas exportadoras do estado, sem distinção de volume exportado, porte ou setor de atividade, selecionadas a partir do relatório de Empresas Exportadoras por Unidades da Federação, disponibilizado pelo Ministério do Desenvolvimento, Indústria e Comércio Exterior (MDIC, n.d.). Identificou-se um total de 1.293 empresas, as quais foram convidadas a participar da pesquisa. Obteve-se um retorno de 71 
questionários completos de empresas industriais, com um índice de respostas de 5,5\%, caracterizando uma margem de erro equivalente a 11,6\% (Barbetta, 2003).

\section{Instrumento de coleta de dados}

O questionário disponibilizado às empresas foi composto por 20 questões, distribuídas em três grupos: perfil da empresa, informações sobre as atividades de exportação e informações sobre as atividades relativas à inovação. Continha questões abertas, mas também questões fechadas desenvolvidas a partir do quadro teórico proposto e, seguindo a escala Likert, variando entre 1 e 7 (menos importante para muito importante), com a opção Não sei responder, a qual foi operacionalizada como valores neutros no decorrer das análises.

Tal questionário foi submetido a um pré-teste com duas empresas exportadoras e seu conteúdo visava obter informações sobre porte, idade e experiência internacional das empresas, motivações para exportação, formas de entrada e de seleção de mercados, utilização de mecanismos formais de incentivo à inovação de exportação, papel das redes de relacionamento, estratégias de geração de inovações, diferencial competitivo nas atividades internacionais, avaliação sobre o grau de inovação da empresa e dados sobre resultados e dispêndios com atividades relacionadas à inovação.

A coleta de dados foi conduzida no período de 25 de setembro a 10 de dezembro de 2009. Optou-se pela abordagem dos dados em termos de subdimensões (cada subitem do questionário) e dimensões (grupos de questões). A utilização das dimensões e a forma de obtenção dos dados basearam-se em comentários de Hair, Anderson, Tatham e Black (2005), de que medidas multivariadas podem ser reunidas, resultando em medidas compostas para representar um conceito, com o objetivo de obter uma perspectiva mais ampla do respondente, utilizando-se da resposta média ou típica de um conjunto de respostas.

Neste estudo, foi adotada a intensidade exportadora (percentual de exportações sobre o total de vendas da empresa) como o indicador principal do desempenho exportador das empresas, juntamente com o número de países atendidos. Reconhece-se, no entanto, que uma combinação de indicadores objetivos e subjetivos poderia fornecer melhores indicadores para o estudo do desempenho exportador, como sugerem diversos autores (Carneiro et al., 2009; Singh, 2009; Sousa, 2004), todavia a revisão dos estudos procedida durante esta pesquisa não conseguiu identificar outros indicadores largamente aceitos e de fácil mensuração pelas empresas. Buscou-se a utilização de indicadores que revelassem as receitas com vendas e o seu crescimento e a lucratividade passada com as exportações, conforme indicadores propostos por Carneiro, Rocha e Silva (2009), entretanto consultas prévias sinalizaram a resistência dos respondentes em fornecer dados sobre faturamento e lucratividade, inviabilizando a utilização de tais indicadores.

Os indicadores utilizados para os mecanismos de transmissão se basearam nas percepções dos executivos sobre os seguintes aspectos:

Quadro institucional: (a) Mecanismos de incentivo à exportação; (b) Quadro institucional para inovação; e (c) Mecanismos de incentivo à inovação.

Rede: (a) Estratégias de cooperação para inovação; (b) Frequência de cooperação para inovação; e (c) Papel das redes.

Inovação: (a) Inovação como diferencial competitivo; (b) Qualidade como diferencial competitivo; (c) Inovações implementadas com efeito sobre as exportações e (d) Diferenciação do produto.

\section{Procedimentos para análise dos dados}

Inicialmente, foram tratados os valores perdidos na base de dados. Este processo minimiza os riscos de redução do tamanho da base de dados, que, em caso de amostras não probabilísticas, gera 
resultados enviesados. Para isso, os valores perdidos foram substituídos pelas médias das variáveis nas quais estão alocados, que, entre as formas de tratamento de valores perdidos, configura-se como o método mais conservador para tratamento dos dados (Allison, 2002; Meyers, Gamst, \& Guarino, 2006).

Em seguida, os dados foram analisados de forma descritiva no intuito de compreender as características destes dados, tais como valores máximos, mínimos, média, desvio padrão, curtose e assimetria (Meyers et al., 2006).

Antes do teste das hipóteses, validade interna, unidimensionalidade, validade discriminante, coeficiente de confiabilidade e variância média extraída de cada dimensão foram verificados. A validade convergente e unidimensionalidade foram testadas por meio da análise fatorial confirmatória (AFC), utilizando estatísticas comom $t$-value, qui-quadrado $\left(X^{2}\right)$, grau de liberdade (gl), coeficiente de determinação $\left(\mathrm{R}^{2}\right)$, raiz média quadrada do erro de aproximação (RMSEA), índice de ajuste comparativo (CFI) e índice de qualidade do ajuste (GFI).

Os índices CFI e GFI foram aplicados a cada dimensão, em que valores mais próximos de 1 representam bom índice de ajuste da dimensão e boa qualidade do ajuste. Em seguida, foi calculada a relação qui-quadrado e grau de liberdade geral, o qual indica bom índice de ajuste dos modelos de medida quando os valores encontrados são menores que 5 e 2, com significância ao nível de 0,05 e 0,01 , respectivamente. Por fim, analisou-se a RMSEA, a qual possui valores aceitáveis entre 0,03 e 0,08 (Kline, 2005; Miles \& Shevlin, 2007).

A validade discriminante foi testada por meio da comparação entre dimensões, com correlações livres entre as dimensões e, em segundo momento, fixadas em 1 . A diferença de qui-quadrado entre ambas as comparações, quando maior que 10.870 (para 1 grau de liberdade), sugere a validade discriminante entre as dimensões (Koufteros, 1999; Stratman \& Roth, 2002).

Por fim, foram testadas a confiabilidade composta, a variância média extraída e a confiabilidade interna, por meio do alfa de Cronbach. Para atender o índice de confiabilidade, as dimensões devem apresentar confiabilidade composta e alfa de Cronbach igual ou superior a 0,7 e AVE igual ou superior a 0,5 (Gudergan, Ringle, Wende, \& Will, 2008; Stratman \& Roth, 2002).

Em termos de modelo estrutural, a análise foi realizada por meio de modelagem de equações estruturais (SEM), a qual permite testar as hipóteses que foram geradas a partir da teoria, sugerindo a confirmação ou não da teoria na amostra em estudo (Hair, Anderson, Tatham, \& Black, 2005; Kline, 2005). Índices como CFI, GFI, RMSEA e relação $X^{2} / \mathrm{gl}$ também foram considerados.

Para o tamanho da amostra, o software SmartPLS foi o mais adequado, contudo, para poder explorar as condições de robustez e de ajustes das dimensões, optou-se pelo uso do software SPSS (AMOS versão 21). No intuito de diminuir as restrições da amostra, optou-se pela purificação do modelo, dessa maneira, eliminando variáveis que possuíam baixa significância no constructo a fim de preservar a relação de cinco a oito respondentes por parâmetro para que viabilizasse a robustez das análises (Gudergan et al., 2008; Ringle, Sarstedt, \& Straub, 2012). Além disso, considerando que o software SPSS para tratamento de dados não contempla o tratamento diferenciado das dimensões formativas e reflexivas, tais questões não foram discutidas no decorrer da análise.

\section{Resultados}

A análise dos dados está baseada na operacionalização de um modelo que, por respaldo teórico, estabelece relações entre o quadro institucional, redes de cooperação, inovação e desempenho exportador. Assim, o modelo foi operacionalizado com auxílio de Modelagem de Equações Estruturais (MEE) para testar as hipóteses das relações propostas no decorrer do estudo. 
Inicialmente, foi realizada a análise descritiva dos itens que compõem as dimensões em estudo para verificar a tendência dos dados e a normalidade dos mesmos. Os resultados da estatística descritiva são apresentados na Tabela 3.

Tabela 3

Análise Descritiva dos Dados

\begin{tabular}{|c|c|c|c|c|c|c|c|c|}
\hline Dimensões & Itens & $\mathbf{N}$ & Min. & Max. & Média & $\begin{array}{l}\text { Desvio } \\
\text { Padrão }\end{array}$ & Assimetria & Curtose \\
\hline Quadro & Incentivo à exportação & 71 & 1 & 7 & 3,01 & 1,419 & ,931 & ,637 \\
\hline \multirow[t]{2}{*}{ Institucional } & Qdo instit. p/inovação & 71 & 2 & 7 & 3,55 & 1,318 & ,468 &,- 614 \\
\hline & Incentivo à inovação & 71 & 1 & 7 & 2,59 & 1,369 & ,989 & ,927 \\
\hline \multirow[t]{3}{*}{ Redes } & Estrat. Coop p/inovação & 71 & 1 & 7 & 4,06 & 1,372 &,- 036 &,- 028 \\
\hline & Freq. Comum p/inovação & 71 & 1 & 7 & 3,63 & 1,149 &, 533 & 1,246 \\
\hline & Papel das Redes & 71 & 1 & 7 & 4,00 & 1,604 & 086 &,- 224 \\
\hline \multirow[t]{4}{*}{ Inovação } & $\begin{array}{l}\text { Inovação c/dif. } \\
\text { competitivo }\end{array}$ & 71 & 1 & 7 & 4,42 & 1,696 &,- 261 &,- 381 \\
\hline & $\begin{array}{l}\text { Qualidade c/dif. } \\
\text { competit. }\end{array}$ & 71 & 4 & 7 & 6,42 &, 889 & $-1,328$ & ,599 \\
\hline & $\begin{array}{l}\text { Inovações e efeito } \\
\text { s/export. }\end{array}$ & 71 & 3 & 7 & 5,30 & 1,074 &,- 054 &,- 593 \\
\hline & Filiais no exterior & 71 & 2 & 7 & 5,56 & 1,065 &,- 644 & 671 \\
\hline \multirow[t]{4}{*}{$\begin{array}{l}\text { Modos de } \\
\text { Entrada }\end{array}$} & $\begin{array}{l}\text { Export. através de } \\
\text { terceiros }\end{array}$ & 71 & 1 & 7 & 3,77 & 2,244 &, 056 & $-1,571$ \\
\hline & Exportação direta & 71 & 1 & 7 & 5,93 & 1,815 & $-1,574$ & 1,059 \\
\hline & $\begin{array}{l}\text { Export. por meio de } \\
\text { redes }\end{array}$ & 71 & 1 & 7 & 2,32 & 1,432 & 1,117 & ,948 \\
\hline & Filiais no exterior & 71 & 1 & 7 & 1,68 & 1,285 & 2,590 & 7,387 \\
\hline Desempenho & Intensidade Exportadora & 71 & 2 & 7 & 4,32 & 1,933 & ,062 & $-1,510$ \\
\hline Exportador & Países atendidos & 71 & 2 & 7 & 5,92 & 1,583 & $-1,413$ & 1,125 \\
\hline
\end{tabular}

Nota. Fonte: dados da pesquisa.

Ao observar a Tabela 3, verifica-se que há uma grande dispersão dos dados que impede a obtenção de resultados acurados sobre a percepção das empresas em relação aos itens pesquisados. A dispersão dos dados pode ser verificada por meio da relação entre desvio padrão e média, a qual se apresenta superior a 0,20 para todos os itens, com exceção do item "Qualidade como diferencial competitivo" na dimensão Inovação.

Apesar da heterogeneidade dos dados, os valores de assimetria e curtose estão dentro dos desejados para estabelecer a normalidade dos dados. De acordo com Kline (2005), espera-se valores inferiores a 3 para assimetria; e inferiores a 10 para curtose para não correr o risco de resultar em problemas na interpretação dos resultados das análises multivariadas.

Em seguida, buscou-se purificar as dimensões por meio da análise fatorial confirmatória, considerando todas as dimensões do modelo ligadas por covariância. As cargas de cada item das escalas obtidas por meio da CFA são apresentadas na Tabela 4. 
Tabela 4

Purificação das Escalas de Medida

\begin{tabular}{|c|c|c|c|c|c|c|c|}
\hline Dimensões & Itens & $\begin{array}{c}\text { Cargas não } \\
\text { padronizada }\end{array}$ & $\begin{array}{c}\text { Cargas } \\
\text { padronizadas }\end{array}$ & $\begin{array}{c}\text { Erro } \\
\text { Padrão }\end{array}$ & t-value & p-value & $\mathbf{R}^{2}$ \\
\hline \multirow{3}{*}{$\begin{array}{l}\text { Quadro } \\
\text { Institucional }\end{array}$} & Incentivo à exportação & 1 & 0,755 & & & & 0,569 \\
\hline & Qdo instit. p/inovação & 0,529 & 0,43 & 0,155 & 3,408 & $* * *$ & 0,185 \\
\hline & Incentivo à inovação & 0,879 & 0,688 & 0,158 & 5,56 & $* * *$ & 0,473 \\
\hline \multirow[t]{3}{*}{ Redes } & Estrat. Coop. p/inovação & 1 & 0,846 & & & & 0,715 \\
\hline & Freq. Comum. p/inovação & 0,828 & 0,836 & 0,114 & 7,277 & $* * *$ & 0,698 \\
\hline & Papel das Redes & 0,811 & 0,587 & 0,164 & 4,943 & $* * *$ & 0,344 \\
\hline \multirow[t]{4}{*}{ Inovação } & Inovação c/dif. competitivo & 1 & 0,631 & & & & 0,398 \\
\hline & Qualidade c/dif. competit. & 0,333 & 0,401 & 0,113 & 2,954 & 0,003 & 0,161 \\
\hline & Inovações e efeito s/export. & 0,901 & 0,897 & 0,187 & 4,815 & $* * *$ & 0,804 \\
\hline & Filiais no exterior & 0,606 & 0,609 & 0,143 & 4,235 & $* * *$ & 0,37 \\
\hline \multirow{4}{*}{$\begin{array}{l}\text { Modos de } \\
\text { Entrada }\end{array}$} & Export. através de terceiros & 1 & 0,235 & & & & 0,055 \\
\hline & Exportação direta & $-0,208$ & $-0,06$ & 0,488 & $-0,426$ & 0,67 & 0,004 \\
\hline & Export. por meio de redes & 2,293 & 0,844 & 1,557 & 1,472 & 0,141 & 0,712 \\
\hline & Filiais no exterior & 1,047 & 0,429 & 0,675 & 1,551 & 0,121 & 0,184 \\
\hline \multirow{2}{*}{$\begin{array}{l}\text { Desempenho } \\
\text { Exportador }\end{array}$} & Intensidade exportadora & 1 & 0,195 & & & & 0,038 \\
\hline & Países atendidos & 4,315 & 1,028 & 7,728 & 0,558 & 0,577 & 1,056 \\
\hline
\end{tabular}

Nota. Fonte: dados da pesquisa. Índices de Ajuste: $X^{2}$ : 162,694; gl: 94; CFI: 0,775; GFI: 0,801; RMSEA: 0,102. *** indica que o item é significantemente diferente de zero ao nível de 0,01 .

De acordo com a Tabela 4, as dimensões Quadro Institucional e Redes apresentaram itens com carga padronizada inferior ao valor recomendado 0,70. Porém os valores da estatística t e $p$-value indicam significância destes itens dentro da dimensão a qual pertencem. Adicionalmente, buscou-se manter um mínimo de três itens para cada dimensão a fim de não comprometer a validade da dimensão.

Já na dimensão Inovação, a qual possui quatro itens, excluiu-se o item com menor carga padronizada e menor $\mathrm{R}^{2}$, de acordo com o recomendado por Kline (2005) e Koufteros (1999). A dimensão Modos de Entrada, por sua vez, obteve baixos valores de carga padronizada, baixa estatística t, baixo $\mathrm{R}^{2}$ e alto $p$-value para seus itens. Assim, optou-se pela exclusão desta dimensão, já que seus itens não mostraram significância dentro do modelo.

Finalmente, a dimensão Desempenho Exportador, variável dependente deste estudo, foi transformada em variável já que os itens que a compõem não apresentaram significância estatística. Assim, com base na carga padronizada, optou-se por manter o número de países atendidos como variável medidora do desempenho exportador, já que a intensidade exportadora apresentou carga padronizada significativamente baixa.

A análise das dimensões demonstrou índices de ajuste (CFI, GFI e RMSEA) com valores abaixo do recomendado pela literatura, o que confirmou a necessidade de eliminação de itens que prejudicam a confiabilidade das dimensões. Logo, após a purificação, as dimensões apresentaram as estatísticas dispostas na Tabela 5. 
Tabela 5

Dimensões após Purificação dos Itens

\begin{tabular}{llcccccc}
\hline Dimensões & Itens & $\begin{array}{c}\text { Cargas não } \\
\text { padronizada }\end{array}$ & $\begin{array}{c}\text { Cargas } \\
\text { padronizadas }\end{array}$ & $\begin{array}{c}\text { Erro } \\
\text { Padrão }\end{array}$ & t-value & p-value & $\mathbf{R}^{\mathbf{2}}$ \\
\hline $\begin{array}{l}\text { Quadro } \\
\text { Institucional }\end{array}$ & Incentivo à exportação & 1 & 0,773 & & & 0,597 \\
& Qdo instit. p/inovação & 0,551 & 0,459 & 0,152 & 3,628 & $* * *$ & 0,21 \\
& Incentivo à inovação & 0,818 & 0,655 & 0,155 & 5,284 & $* * *$ & 0,43 \\
\hline Redes & Estrat. coop. p/inovação & 1 & 0,842 & & & 0,709 \\
& Freq. comum. p/inovação & 0,834 & 0,838 & 0,115 & 7,258 & $* * *$ & 0,703 \\
& Papel das redes & 0,818 & 0,589 & 0,165 & 4,959 & $* * *$ & 0,347 \\
\hline Inovação & Inovação c/dif. competitivo & 1 & 0,668 & & & 0,446 \\
& Inovações e efeito s/export. & 0,813 & 0,857 & 0,171 & 4,766 & $* * *$ & 0,735 \\
& Filiais no exterior & 0,57 & 0,606 & 0,134 & 4,243 & $* * *$ & 0,368 \\
\hline $\begin{array}{l}\text { Desempenhor } \\
\text { Exportador }\end{array}$ & Número de países & 1 & 1 & & & & 1
\end{tabular}

Nota. Fonte: dados da pesquisa. Índices de Ajuste: $\mathrm{X}^{2}$ : 48,784; gl: 24; CFI: 0,910; GFI: 0,895; RMSEA: 0,958. *** indica que o item é significantemente diferente de zero ao nível de 0,01 .

Após a eliminação dos itens, procedeu-se para a análise de confiabilidade das dimensões por meio da confiabilidade composta, variância extraída e alfa de Cronbach. Os resultados estão dispostos na Tabela 6.

Tabela 6

Análise da Confiabilidade das Dimensões

\begin{tabular}{cccc}
\hline Dimensões & Confiabilidade Composta & Variância Extraída & Alfa de Cronbach \\
\hline Quadro Institucional & 0,67 & 0,41 & 0,641 \\
Redes & 0,81 & 0,59 & 0,763 \\
Inovação & 0,76 & 0,52 & 0,714 \\
\hline
\end{tabular}

Nota. Fonte: dados da pesquisa.

De acordo com a Tabela 6, observa-se que as dimensões Redes e Inovação apresentaram coeficientes de confiabilidade que são considerados pela literatura como adequados. Já a dimensão quadro institucional apresentou confiabilidade composta e alfa de Cronbach pouco abaixo de 0,70 e variância extraída pouco abaixo de 0,5 , os quais são valores considerados adequados. No entanto, de acordo com Hair et al. (2005) e Nunnally (1978), índices inferiores a 0,70 e superiores a 0,50 para os coeficientes de confiabilidade podem ser aceitos quando se trata de modelos exploratórios, como no caso do presente estudo.

Por fim, analisou-se a validade discriminante das dimensões. Esta análise foi feita em pares, comparando a diferença de qui-quadrado entre a correlação livre e correlação fixada em 1 entre as dimensões. A diferença de qui-quadrado superior a 10,827 para 1 grau de liberdade confere a validade discriminante entre dimensões a 0.01 e superior a 3,841 ao nível de 0.05 (Stratman \& Roth 2002). 
Tabela 7

Validade Discriminante das Dimensões

\begin{tabular}{llccccc}
\hline \multicolumn{2}{c}{ Pares de Dimensões } & \multicolumn{2}{c}{ Livre } & \multicolumn{2}{c}{ Fixo } & Diferença de \\
\cline { 3 - 6 } & & $\boldsymbol{X}^{\mathbf{2}}$ & gl & $\boldsymbol{X}^{\mathbf{2}}$ & Gl & $\boldsymbol{X}^{\mathbf{2}}$ \\
\hline Quadro Institucional & Redes & 15,910 & 8 & 15,963 & 9 & 0,053 \\
Quadro Institucional & Inovação & 23,489 & 8 & 23,621 & 9 & 0,132 \\
Redes & Inovação & 7,426 & 8 & 11,602 & 9 & 4,176 \\
\hline
\end{tabular}

Nota. Fonte: dados da pesquisa.

De acordo com a Tabela 7, a validade discriminante entre as dimensões só é percebida entre Redes e Inovação, com diferença de qui-quadrado superior a 3,841, o que confere uma confiabilidade de $95 \%$. A mesma validade não foi percebida entre Quadro Institucional e Redes e entre Quadro Institucional e Inovação.

Apesar da colinearidade existente entre os constructos, optou-se por analisar as relações entre eles, de forma a rejeitar ou não rejeitar as hipóteses. Assim, a análise das relações entre constructos foi feita por meio da Análise Fatorial Confirmatória, conforme apresentado na Figura 1.

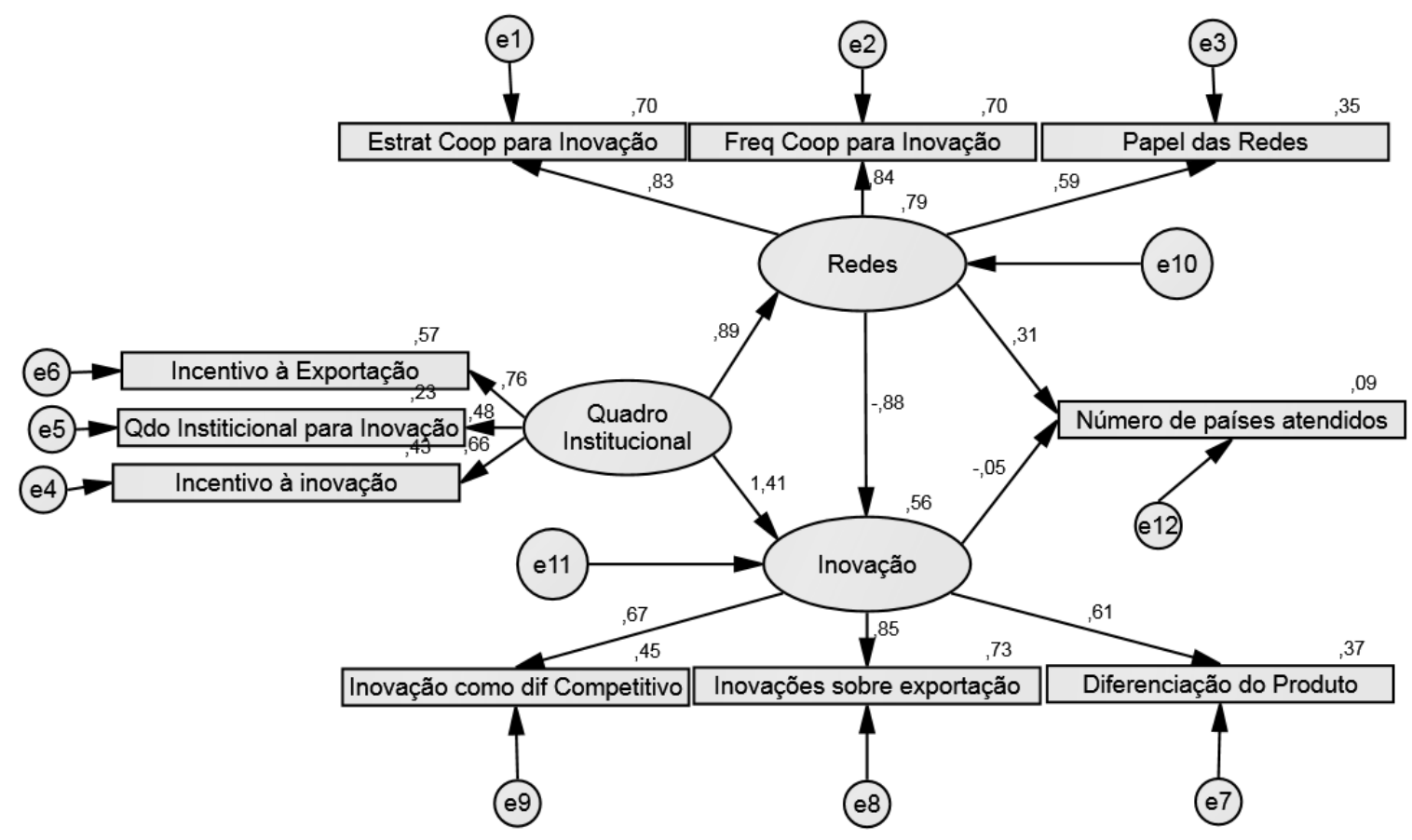

Figura 1. Análise das Relações entre Constructos.

Fonte: dados da pesquisa.

De uma forma geral, de acordo com a Figura 1, existe colinearidade entre Quadro Institucional e Inovação, o que confirma os achados da Tabela 7. Redes e Inovação possuem alta correlação negativa; e Inovação possui influência próxima a zero sobre o desempenho exportador medido pelo número de países atendidos.

Embora o efeito das inovações para exportação tenha se mostrado significante, sua influência por meio da dimensão inovação sobre o desempenho exportador foi insignificante $(-0,05)$. Estudos anteriores relatam uma relação direta entre inovação e desempenho exportador, o que não ocorreu com a amostra analisada. No entanto os estudos destacam que um dos principais efeitos das inovações é o 
acesso a novos mercados (Filipescu et al., 2009; Knight \& Cavusgil, 2004; Roper \& Love, 2002), juntamente com a propensão das empresas a exportar (De Negri \& Freitas, 2004; Nguyen et al., 2008). No presente estudo, não foi analisado este aspecto especificamente.

Destaca-se que a relação entre inovação e desempenho exportador não é linear e tende a ressaltar comportamentos diferentes entre indústrias e empresas. Autores (Guan \& Ma, 2003; Mais \& Amal, 2011) mostraram que as atividades do núcleo de inovação (P\&D, marketing, etc.) não necessariamente tendem a influenciar positivamente o desempenho exportador de empresas. Entretanto há autores que indicam que, numa perspectiva de longo prazo, o desempenho exportador e a diversificação dos mercados estão estritamente relacionados à melhoria da capacidade de inovação das empresas (Guan \& Ma, 2003). Pla-Barber e Alegre (2007), numa análise da indústria de biotecnologia, mostraram que a relação entre inovação e intensidade exportadora é positivamente correlacionada, entretanto tal relação não necessariamente se confirma em outras indústrias, como no caso de empresas brasileiras, que apresentam baixa dotação tecnológica na sua pauta de exportação (De Negri \& Freitas, 2004). Para Basile (2001), a partir de análise das empresas da indústria de manufaturados na Itália, mostrou-se que o efeito da inovação é heterogêneo entre as empresas, o que significa que, ceteris paribus, sob as mesmas restrições cambiais ou de demanda, empresas inovadoras tendem a registrar um desempenho exportador maior do que empresas não inovadoras.

Adicionalmente, o nível de desenvolvimento tecnológico da amostra pode ainda não se configurar como um diferencial competitivo no mercado internacional, o que seria convergente com estudo de Filipescu et al. (2009), com o qual verificaram que muitas empresas ainda se concentram em inovações incrementais nos seus produtos, o que não se reflete em melhor desempenho exportador, mas em manutenção dos níveis de exportação.

Deste modo, optou-se por excluir a dimensão inovação do modelo. Primeiro, por apresentar resultados conflitantes na literatura de negócios internacionais e, segundo, para preservar as condições de robustez do modelo. Assim, optou-se por manter apenas a dimensão Redes como mecanismo de transmissão dos efeitos institucionais sobre o desempenho exportador.

A dimensão Inovação pode ser explicada, em 56\%, quando considerada dependente das dimensões Quadro Institucional e Redes. Nesta equação, apesar da dimensão Redes se constituir variável independente, e mesmo estando relacionada teoricamente com o surgimento de inovações, não apresentou resultados significativos e negativos quanto a sua influência sobre as inovações. Dessa forma, entende-se que pouca inserção das empresas em redes e os mecanismos de incentivos à exportação e inovação propiciados pelo quadro institucional podem influenciar no surgimento de inovações.

Por se tratar de um processo complexo e de permanente aprendizagem, seria esperado encontrar relação positiva entre as redes e a inovação (Freeman, 1995). No entanto a amostra analisada não forneceu suporte à hipótese, sinalizando que, no grupo de empresas estudado, a inovação é prioritariamente um processo endógeno. Entende-se, portanto, que outros fatores do quadro institucional sejam mais relevantes para gerar inovações do que a cooperação com outros agentes.

Dado os resultados apresentados nas Tabela 7 e Figura 1 (colinearidade entre constructos e baixa influência sobre o desempenho exportador), optou-se pela exclusão da dimensão Inovação do modelo de análise. Assim, o novo modelo de análise segue apresentado na Figura 2. 


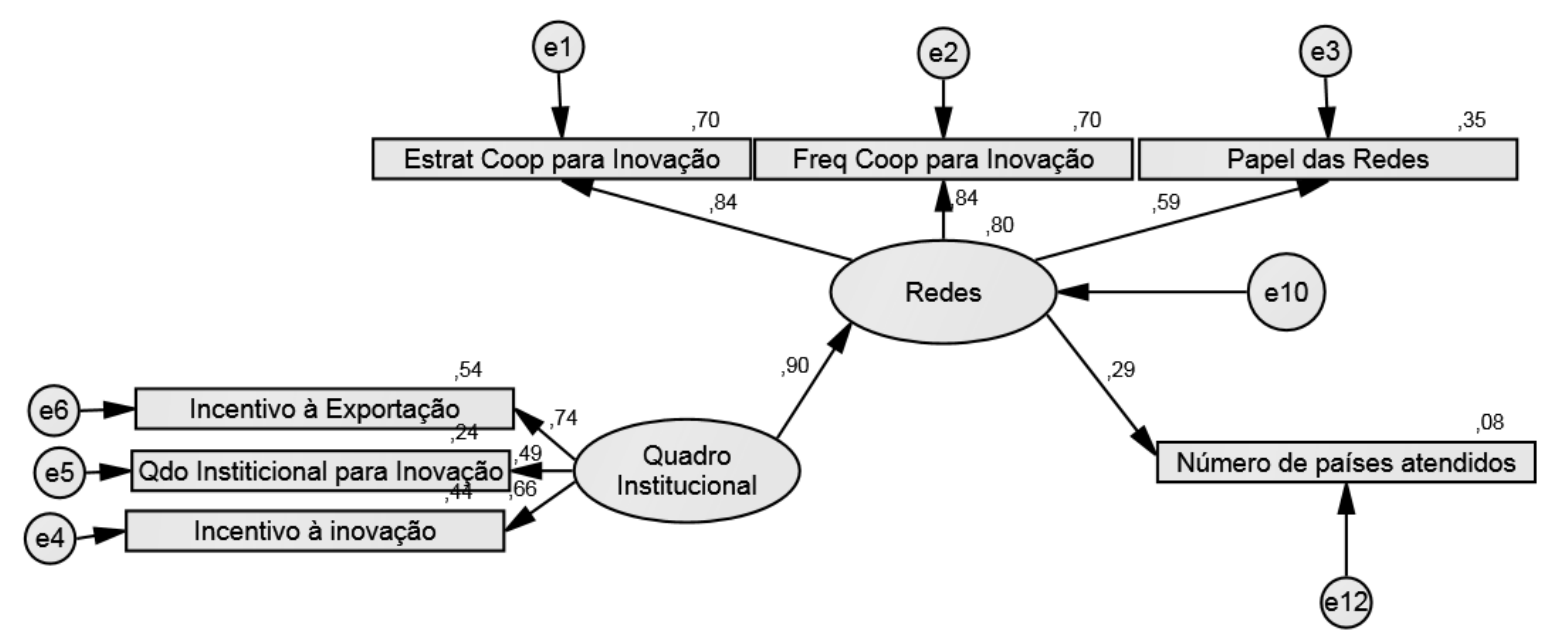

Figura 2. Modelo de Análise Purificado.

Fonte: dados da pesquisa.

O quadro institucional é composto pelas variáveis: incentivo à exportação, quadro institucional para inovação e incentivo à inovação. De acordo com a Figura 2, os mecanismos de incentivo à exportação têm se mostrado como o indicador mais representativo no Quadro Institucional, com carga fatorial superior a 0,70. Em relação à dimensão Redes, as estratégias de cooperação para inovação e a frequência de cooperação para inovação mostraram-se significativas nesta dimensão.

Em termos de relação entre as dimensões, o quadro institucional apresenta alta influência na inserção das empresas em redes $(0,90)$, não rejeitando a hipótese 1 . Tal observação corrobora o argumento de Hollingsworth (2000), quando afirma que o quadro institucional exerce efeito sobre os padrões de envolvimento em redes (arranjos institucionais) e sobre as inovações de uma nação (resultados e desempenho).

A inserção das empresas em redes, por sua vez, tem influenciado no desempenho exportador das empresas, quando medido pelo número de países atendidos, em 0,29. Os resultados confirmam as afirmações de diversos autores acerca do efeito positivo das redes sobre o desempenho exportador das empresas (Coviello \& Munro, 1995; Johanson \& Mattson, 1988), embora com um grau de influência pouco significativo. Desta forma, a hipótese 2 também não foi rejeitada.

A seguir, apresenta-se, na Tabela 8, a síntese dos resultados.

Tabela 8

\section{Hipóteses Testadas no Trabalho e seus Resultados}

\section{HIPÓTESES}

\section{RESULTADO}

H1: O quadro institucional influencia positivamente na inserção das empresas em redes de cooperação.

Confirmada

H2: O quadro institucional influencia positivamente no desenvolvimento de inovações.

Não há suporte

H3: A inserção em redes influencia positivamente no desenvolvimento de inovações.

Não Confirmada

H4: A inserção em redes influencia positivamente no desempenho exportador.

Confirmada

H5: O desenvolvimento de inovações influencia positivamente no desempenho exportador.

Nota. Fonte: dados da pesquisa. 


\section{Conclusão}

A busca pela identificação dos fatores que determinam o desempenho exportador das empresas avança na medida em que expande a variedade de variáveis analisadas. A importância da experiência internacional é fator consolidado entre os acadêmicos de negócios internacionais, no entanto não é suficiente para explicar altos desempenhos de empresas de pequeno e médio porte e/ou processos de internacionalização acelerada, surgindo, assim, a necessidade de investigar novos fatores condicionantes do desempenho exportador. Neste sentido, o presente estudo propôs uma abordagem institucional para buscar compreender o desempenho exportador das empresas analisadas. Estabeleceu, para tanto, como diretrizes as seguintes questões: (a) Quais são os efeitos do quadro institucional sobre o desempenho exportador?; (b) Considerando que o efeito do quadro institucional nem sempre é direto, a partir de quais mecanismos o quadro institucional exerce tais efeitos sobre o desempenho exportador?

Verificou-se que o quadro institucional do país exerce efeito positivo sobre as empresas pesquisadas no que se refere à inserção em redes e à geração de inovações. Considerando estes resultados e estudos prévios que estabelecem a relação destas variáveis e o desempenho exportador (Coviello \& Munro, 1995; Freeman, 1995; Johanson \& Mattson, 1988), deveria ser possível afirmar que estes seriam os efeitos do quadro institucional, porém esta hipótese não se confirmou para a amostra, tendo em vista as hipóteses testadas no modelo proposto neste estudo.

Ao considerar a utilização, neste trabalho, dos mecanismos formais (regulamentação tributária e as práticas de financiamento) como indicadores do quadro institucional favorável às atividades internacionais, assume-se que um país exerce efeito sobre o desempenho exportador das suas empresas a partir da formatação e disponibilização de mecanismos formais de incentivo. Tais resultados foram encontrados em outros estudos (Alvarez, 2004; Klotzle \& Thomé, 2006; Ling-Yee \& Ogunmokum, 2001) que destacaram o papel da promoção comercial e políticas públicas e de incentivos sobre o desempenho exportador de empresas no país de origem, ou das condições de liberdade econômica e redução das barreiras tarifárias no caso dos países de destino (Carneiro et al., 2011; Estrin, Meyer, Wright, \& Foliano, 2008).

De maneira geral, os resultados da pesquisa não estão em concordância com pesquisas feitas em países desenvolvidos, as quais mostraram que há uma correlação direta entre desempenho exportador de empresas e estratégias que resultam na oferta de novos produtos e serviços (Kim \& Mauborgne, 2005), ou cujo acesso a novos mercados é diretamente relacionado à capacidade inovadora da empresa (Filipescu et al., 2009; Knight \& Cavusgil, 2004; Roper \& Love, 2002), bem como a propensão das empresas a exportar (Nguyen et al., 2008; Roper \& Love, 2002).

Em relação à amostra que subsidiou o presente estudo, verificou-se que as empresas que se consideram mais inovadoras não são aquelas que apresentam maior desempenho exportador. De maneira análoga, altos desempenhos nas exportações nem sempre estão relacionados a altos níveis de inovação. Neste sentido, estima-se que as estruturas de $\mathrm{P} \& \mathrm{D}$ podem estar direcionadas mais para o aperfeiçoamento dos produtos e processos disponíveis (inovações incrementais) do que em gerar produtos efetivamente novos para o mercado. Além disso, as empresas mais inovadoras podem não estar orientadas para a atuação nos mercados externos. Considerando que o Brasil é um país com grandes dimensões e com níveis relevantes de crescimento, pode se justificar um interesse menor das empresas em avançar nas atividades internacionais.

A condução do estudo demonstrou que a inter-relação entre quadro institucional, redes, inovação e desempenho exportador pode representar uma configuração mais complexa do que se supunha inicialmente. Enquanto estudos internacionais dão indícios de correlações positivas sobre esses elementos do cenário empresarial, a sua avaliação efetiva enfrenta dificuldades de diferentes naturezas, passando desde a obtenção de dados até a definição de indicadores confiáveis para sua mensuração. 
A premissa do presente estudo é de que o quadro institucional do país de origem não age diretamente sobre o desempenho exportador e que existem certos mecanismos por meio dos quais tal quadro pode influenciar no desempenho exportador de empresas. Os mecanismos possíveis de serem identificados, de acordo com Hollingsworth (2000), foram redes de relacionamento e inovações, sendo as duas variáveis, também, consideradas na literatura de negócios internacionais como fatores determinantes neste processo. Os resultados mostraram que, efetivamente, existem correlações positivas entre o quadro institucional e inovações e redes de relacionamento. Entretanto o mecanismo de transmissão que foi evidenciado se refere apenas ao fator redes e não ao fator inovação. Deste modo, conclui-se que o impacto do quadro institucional se mostra restrito à sua abrangência e extensão, não permitindo se constituir como quadro de alavancagem das exportações de empresas, embora existam instituições atuantes para promover o ambiente de negócios internacionais. É uma conclusão importante na medida em que mostra que a existência de instituições, por si, não é suficiente para dar suporte à competitividade externa das empresas, sendo necessário transmitir as vantagens de maneira eficiente para as organizações. Neste sentido, o papel da inovação, por representar uma dimensão de manter ou criar novos mercados e atender a novas demandas, é crítico para refletir tais vantagens na estratégia das empresas.

As limitações da amostra, assim como o uso apenas de indicador objetivo de medição do desempenho exportador, representam restrições para a análise de um fenômeno com tamanha complexidade. Sugere-se, portanto, para futuros estudos, que se procure comparar diferentes regiões do Brasil e que sejam adotados diversos indicadores (objetivos e subjetivos) de medição do desempenho exportador.

\section{Referências}

Allison, P. D. (2002). Missing data: quantitative applications in the social sciences. British Journal of Mathematical and Statistical Psychology, 55(1), 193-196. doi: 10.1348/000711002159653

Alvarez, R. E. (2004). Sources of export success in small-and medium-sized enterprises: the impact of public programs. International Business Review, 13(3), 383-400. doi: 10.1016/j.ibusrev.2004.01.002

Amal, M., \& Freitag, A. R., Filho (2010). Internationalization of small-and medium-sized enterprises: a multi case study. European Business Review, 22(6), 608-623. doi: $10.1108 / 09555341011082916$

Awuah, G. B., \& Amal, M. (2011). Impact of globalization: the ability of less developed countries' (LDCs') firms to cope with opportunities and challenges. European Business Review, 23(1), 120-132. doi: 10.1108/09555341111098026

Barbetta, P. R. (2003). Estatística aplicada às ciências sociais (5a ed.). Florianópolis: Editora da UFSC.

Basile, R. (2001). Export behaviour of Italian manufacturing firms over the nineties: the role of innovation. Research policy, 30(8), 1185-1201. doi: 10.1016/S0048-7333(00)00141-4

Buckley, P. J., \& Ghauri, P. N. (2004). Globalization, economic geography, and the strategy of multinational enterprises. Journal of International Business Studies, 35(2), 81-98. doi: 10.1057/palgrave.jibs.8400076

Burns, T. R., \& Flam, H. (1987). The structuring of markets and other distributive systems. In T. R. Burns \& H. Flam (Eds.), The shaping of social organization: social rule system theory with applications (pp. 123-151). Beverly Hills, CA: Sage Press. 
Campbell, J. L., Hollingsworth, J. R., \& Lindberg, L. (Eds.). (1991). The governance of the American economy. Cambridge; New York: Cambridge University Press.

Carneiro, J., Rocha, A. da, \& Silva, J. F. da (2009). Proposal of a validation framework for a new measurement model and its application to the export performance construct. Brazilian Administration Review, 6(4), 331-353. Recuperado de http://www.scielo.br/pdf/bar/v6n4/v6n4a05. doi: 10.1590/S1807-76922009000400005

Carneiro, J., Rocha, A. da, \& Silva, J. F. da (2011). Determinants of export performance: a study of large Brazilian manufacturing firms. Brazilian Administration Review, 8(2), 107-132. Recuperado de http://www.scielo.br/pdf/bar/v8n2/02.pdf. doi: 10.1590/S180776922011000200002

Cheng, H.-L., \& Yu, C.-W. J. (2008). Institutional pressures and initiation of internationalization: evidence from Taiwanese small- and medium-sized enterprises. International Business Review, 17(3), 331-348. doi: 10.1016/j.ibusrev.2008.01.006

Coviello, N. E., \& Munro, H. J. (1995). Growing the entrepreneurial firm: networking for international market development. European Journal of Marketing, 29(7), 49-61. doi: $10.1108 / 03090569510095008$

De Negri, J. A., \& Freitas, F. (2004). Inovação tecnológica, eficiência de escala e as exportações brasileiras [Texto para discussão, $\left.\mathrm{N}^{\circ} 1044\right]$ ]. Brasília, DF: IPEA.

Diegues, A. C., \& Roselino, J. E. (2006). Interação, aprendizado tecnológico e inovativo no pólo de TIC da região de Campinas: uma caracterização com ênfase nas atividades desenvolvidas pelas empresas beneficiárias da Lei de Informática. Revista Brasileira de Inovação, 5(2), 373-402.

Estrin, S., Meyer, K. E., Wright, M., \& Foliano, F. (2008). Export propensity and intensity of subsidiaries in emerging economies. International Business Review, 17(5), 574-586. doi: 10.1016/j.ibusrev.2008.04.002

Filipescu, D. A., Rialp, A., \& Rialp, J. (2009). Internationalization and technological innovation: empirical evidence on their mutual relationship. Advances in International Marketing, 20, 125154. doi: 10.1108/S1474-7979(2009)0000020008

Freeman, C. (1995). The 'National System of Innovation' in historical perspective. Cambridge Journal of Economics, 19(1), 5-24.

Gomel, M. M. (2005). O papel da capacitação tecnológica no desempenho exportador da indústria brasileira de software (Tese de doutorado). Universidade de São Paulo, São Paulo, SP, Brasil.

Gomes, C. M., \& Kruglianskas, I. (2009). A influência do porte no comportamento inovador da empresa. Revista de Administração e Inovação, 6(2), 5-27. doi: 10.5585/rai.v6i2.285

Guan, J., \& Ma, N. (2003). Innovative capability and export performance of Chinese firms. Technovation, 23(9), 737-747. doi: 10.1016/S0166-4972(02)00013-5

Gudergan, S. P., Ringle, C. M., Wende, S., \& Will, A. (2008). Confirmatory tetrad analysis in PLS path modeling. Journal of Business Research, 61(12), 1238-1249. doi: 10.1016/j.jbusres.2008.01.012

Hair, J. F., Jr., Anderson, R. E., Tatham, R. L., \& Black, W. C. (2005). Fundamentos de métodos de pesquisa em administração. Porto Alegre: Bookman.

Harris, S., \& Wheeler, C. (2005). Entrepreneurs' relationships for internationalization: functions, origins and strategies. International Business Review, 14(2), 187-207. doi: 10.1016/j.ibusrev.2004.04.008 
Hollingsworth, J. R. (1991). The logic of coordinating American manufacturing sectors. In J. L. Campbell, J. R. Hollingsworth, \& L. Lindberg (Eds.), The governance of the American economy (pp. 35-73). Cambridge; New York: Cambridge University Press.

Hollingsworth, J. R. (1997). Continuities and changes in social systems of production: the cases of Japan, Germany, and the United States'. In J. R. Hollingsworth \& R. Boyer (Eds.), Contemporary capitalism: the embeddedness of institutions (pp. 265-310). Cambridge; New York: Cambridge University Press.

Hollingsworth, J. R. (2000). Doing institutional analysis: implications for the study of innovations. Review of International Political Economy, 7(4), 595-644. doi: 10.1080/096922900750034563

Hollingsworth, J. R., Hage, J., \& Hanneman, R. A. (1990). State intervention in medical care: consequences for Britain, France, Sweden, and the United States, 1890-1970. Ithaca, NY: Cornell University Press.

Hollingsworth, J. R., \& Hanneman, R. (1982). Working-class power and the political economy of western capitalist societies. Comparative Social Research, 5, 61-80.

Hollingsworth, J. R., \& Lindberg, L. (1985). The governance of the American economy: the role of markets, clans, hierarchies, and associative behavior. In W. Streeck \& P. C. Schmitter (Eds.), Private interest government: beyond market and state (pp. 221-254). London; Beverly Hills: Sage Publications.

Hollingsworth, J. R., Schmitter, P., \& Streeck, W. (Eds.). (1994). Governing capitalist economies: performance and control of economic sectors. New York: Oxford University Press.

Hollingsworth, J. R., \& Streeck, W. (1994). Countries and sectors: performance, convergence and competitiveness. In J. R. Hollingsworth, P. Schmitter, \& W. Streeck (Eds.), Governing capitalist economies: performance and control of economic sectors (pp. 270-300). New York: Oxford University Press.

Johanson, J., \& Mattson, L. G. (1988). Internationalisation in industrial systems - a network approach. In N. Hood \& J. E. Valhne (Eds.), Strategies in global competition (pp. 287-314). Croom Helm: Dover.

Johanson, J., \& Vahlne, J.-E. (1977). The internationalization process of the firm-a model of knowledge development and increasing foreign market commitments. Journal of International Business Studies, 8(1), 23-32. doi: 10.1057/palgrave.jibs.8490676

Johanson, J., \& Vahlne, J.-E. (2009). The Uppsala internationalization process model revisited: from liability of foreignness to liability of outsidership. Journal of International Business Studies, 40(9), 1411-1431. doi: 10.1057/jibs.2009.24

Kim, W. C., \& Mauborgne, R. (2005). Blue ocean strategy: how to create uncontested market space and make the competition irrelevant. Boston: Harvard Business School.

Kline, R. B. (2005). Principles and practice of structural equation modeling (2nd ed.). New York: The Guilford Press.

Klotzle, M. C., \& Thomé, C. C. (2006). Fatores associados ao desempenho exportador de micros, pequenas e médias empresas brasileiras. Revista de Administração,4l(3), 339-346. doi: $10.1590 /$ S0080-21072006000300010

Knight, G. A., \& Cavusgil, S. T. (2004). Innovation, organizational capabilities, and the born-global firm. Journal of International Business Studies, 35(4), 124-141. doi: 10.1057/palgrave.jibs.8400071 
Kostova, T. (1997, August). Country institutional profile: concept and measurement. Proceedings of the Academy of Management, Boston, MA, USA, 1.

Kostova, T., \& Zaheer, S. (1999). Organizational legitimacy under conditions of complexity: the case of the multinational enterprise. Academy of Management Review, 24(1), 64-81. doi: 10.5465/AMR.1999.1580441

Koufteros, X. A. (1999). Testing a model of pull production: a paradigm for manufacturing research using structural equation modeling. Journal of Operations Management, 17(4), 467-488. doi: 10.1016/S0272-6963(99)00002-9

Kshetri, N. (2007). Institutional factors affecting offshore business process and information technology outsourcing. Journal of International Management, 13(1), 38-56. doi: 10.1016/j.intman.2006.05.00

Kuivalainen, O., Sundqvist, S., \& Servais, P. (2007). Firms' degree of born-globalness, international entrepreneurial orientation and export performance. Journal of World Business, 42(3), 253-267. doi: 10.1016/j.jwb.2007.04.010

Lee, J., \& Habte-Giorgis, B. (2004). Empirical approach to the sequential relationships between firm strategy, export activity, and performance in U.S. manufacturing firms. International Business Review, 13(1), 101-129. doi: 10.1016/j.ibusrev.2003.05.003

Leonidou, L. C., Katsikeas, C. S., \& Samiee, S. (2002). Marketing strategy determinants of export performance: a meta-analysis. Journal of Business Research, 55(1), 51-67. doi: 10.1016/S01482963(00)00133-8

Ling-Yee, L., \& Ogunmokum, G. O. (2001). The influence of interfim relational capabilities on export advantage and performance: an empirical analysis. International Business Review, 10(4), 399420. doi: 10.1016/S0969-5931(01)00023-3

Loane, S., \& Bell, J. (2006). Rapid internationalisation among entrepreneurial firms in Australia, Canada, Ireland and New Zealand: an extension to the network approach. International Marketing Review, 23(5), 467-485. doi: 10.1108/02651330610703409

Lu, Y., Tsang, E. W. K., \& Peng, M. W. (2008). Knowledge management and innovation strategy in the Asia Pacific: toward an institution-based view. Asia Pacific Journal of Management, 25(3), 361-374. doi: 10.1007/s10490-008-9100-9

Mais, I., \& Amal, M. (2011). Determinants of export performance: an institutional approach. Latin American Business Review, 12(4), 281-307. doi: 10.1080/10978526.2011.633029

Majocchi, A., Bacchiocchi, E., \& Mayrhofer, U. (2005). Firm size, business experience and export intensity in SMEs: a longitudinal approach to complex relationships. International Business Review, 14(6), 719-738. doi: 10.1016/j.ibusrev.2005.07.004

Mathews, J. A., \& Zander, I. (2007). The international entrepreneurial dynamics of accelerated internationalisation. Journal of International Business Studies, 38(3), 387-403. doi: 10.1057/palgrave.jibs.8400271

Meyer, K. E., Estrin, S., Bhaumik, S. K., \& Peng, M. W. (2009). Institutions, resources, and entry strategies in emerging economies. Strategic Management Journal, 30(1), 61-80. doi: $10.1002 /$ smj. 720

Meyers, L. S., Gamst, G., \& Guarino, A. J. (2006). Applied multivariate research: design and interpretation. London: Sage. 
Miles, J., \& Shevlin, M. (2007). A time and a place for incremental fit indices. Personality and Individual Differences, 42(5), 869-874. doi: 10.1016/j.paid.2006.09.022

Ministério do Desenvolvimento, Indústria e Comércio Exterior. (n.d.). Empresas brasileiras exportadoras por países de destino ou por Unidade da Federação. Recuperado de $\mathrm{http} / / / \mathrm{www}$. desenvolvimento.gov.br/sitio/interna/interna.php?area=5\&menu=1444\&refr=603

Moen, Ø., Gavlen, M., \& Endresen, I. (2004). Internationalization of small, computer software firms: entry forms and market selection. European Journal of Marketing, 38(9/10), 1236-1251. doi: $10.1108 / 03090560410548951$

Nguyen, A. N., Quang Pham, N., Nguyen, C. D., \& Nguyen, N. D. (2008). Innovation and exports in Vietnam's SME sector. The European Journal of Development Research, 20(2), 262-280. doi: $10.1080 / 09578810802060801$

North, D. C. (1990). Institutions, institutional change and economic performance. Cambridge: Cambridge University Press.

Nunnally, J. C. (1978). Psychometric theory. New York: McGraw-Hill Company.

Papadopoulos, N., \& Martín Martín, O. (2010). Toward a model of relationship between internationalization and export performance. International Business Review, 19(4), 388-406. doi: 10.1016/j.ibusrev.2010.02.003

Peng, M. W., \& Heath, P. (1996). The growth of the firm in planned economies in transition: institutions, organizations, and strategic choice. Academy of Management Review, 21(2), 492528. doi: 10.5465/AMR.1996.9605060220

Peng, M. W., Sun, L. S., Pinkham, B., \& Chen, H. (2009). The institution-based view as a third leg for a strategy tripod. Academy of Management Perspectives, 23(3), 63-71.

Pla-Barber, J., \& Alegre, J. (2007). Analysing the link between export intensity, innovation and firm size in a science-based industry. International Business Review, 16(3), 275-293. doi: 10.1016/j.ibusrev.2007.02.005

Porter, M. E. (1999). Estratégia competitiva: técnicas para análise de indústrias e da concorrência (16a ed.). Rio de Janeiro: Campus.

Powell, W. W., \& DiMaggio, P. J. (Eds.). (1991). The new institutionalism in organizational analysis. Chicago: University of Chicago Press.

Puga, F. P. (2006, agosto 18). Câmbio afeta exportadores de forma diferenciada. BNDES: Visão do Desenvolvimento, (9). Recuperado de http://www.bndes.gov.br/SiteBNDES/export/sites/default/bndes_pt/Galerias/Arquivos/conheci mento/visao/visao_09.pdf

Ringle, C. M., Sarstedt, M., \& Straub, D. W. (2012). Editor's comments: a critical look at the use of PLS-SEM in MIS quarterly. MIS quarterly, 36(1), iii-xiv.

Rodriguez, J. L., \& Rodriguez, R. M. G. (2005). Technology and export behavior: a resource-based view approach. International Business Review, 14(5), 539-557. doi: 10.1016/j.ibusrev.2005.07.002

Roper, S., \& Love, J. H. (2002). Innovation and export performance: evidence from the UK and German manufacturing plants. Research Policy, 31(7), 1087-1102. doi: 10.1016/S00487333(01)00175-5 
Schumpeter, J. A. (1934). The theory of economic development: an inquiry into profits, capital, credit, interest, and the business cycle (Vol. 55). New Brunswick, New Jersey: Transaction Publishers.

Scott, W. R. (1995). Institutions and organizations. Thousand Oaks: Sage Publications.

Singh, D. A. (2009). Export performance of emerging market firms. International Business Review, 18(4), 321-330. doi: 10.1016/j.ibusrev.2009.03.002

Sousa, C. M. P. (2004). Export performance measurement: an evaluation of the empirical research in the literature. Academy of Marketing Science Review, 2004(9), 1-23.

Sousa, C. M. P., \& Bradley, F. (2008). Cultural distance and psychic distance: refinements in conceptualisation and measurement. Journal of Marketing Management, 24(5-6), 467-488. doi: $10.1362 / 026725708 \times 325959$

Stoian, M.-C., Rialp, A., \& Rialp, J. (2011). Export performance under the microscope: a glance through Spanish lenses. International Business Review 20(2), 117-135. doi: 10.1016/j.ibusrev.2010.07.002

Stratman, J. K., \& Roth, A. V. (2002). Enterprise resource planning (ERP) competence constructs: two- stage multi- item scale development and validation*. Decision Sciences, 33(4), 601-628. doi: $10.1111 / \mathrm{j} .1540-5915.2002 . t b 01658 . x$

Tödtling, F., \& Kaufmann, A. (2002). SMEs in regional innovation systems and the role of innovation support - The case of upper Austria. Journal of Technology Transfer, 27(1), 15-26. doi: 10.1023/A:1013140318907

Verwaal, E., \& Donkers, B. (2002). Firm size and export intensity: solving an empirical puzzle. Journal of International Business Studies, 33(3), 603-613. doi: 10.1057/palgrave.jibs.8491035

Weerawardena, J., Mort, G. S., Liesch, P. W., \& Knight, G. (2007). Conceptualizing accelerated internationalization in the born-global firm: a dynamic capabilities perspective. Journal of World Business, 42(3), 294-306. doi: 10.1016/j.jwb.2007.04.004

Wood, G., \& Demirbag, M. (2012). Handbook of institutional approaches to international business. Cheltenham, UK: Edward Elgar Publishing.

Xu, D., \& Shenkar, O. (2002). Institutional distance and the multinational enterprise. Academy of Management Review, 27(4), 608-618.

Yin, R. K. (2005). Estudo de caso: planejamento e métodos (3a ed.). Porto Alegre: Bookman.

Zhou, L., Wu, W.-P, \& Luo, X. (2007). Internationalization and the performance of born-global SMEs: the mediating role of social networks. Journal of International Business Studies, 38(4), 673-690. doi: 10.1057/palgrave.jibs.8400282 